\title{
Previous gardening experience and gardening enjoyment is related to vegetable preferences and consumption among low-income elementary school children
}

\section{INTRODUCTION}

Diets rich in fruits and vegetables (F\&V) are known to have important health benefits.

Studies suggest that increased F\&V consumption is associated with lower risk of coronary heart disease, type 2 diabetes, some cancers, and all-cause mortality. ${ }^{1-3}$ Fiber content and essential micronutrients (such as vitamins, minerals, and a diverse range of phytochemicals, especially antioxidants) concentrated in F\&V comprise their health benefits. ${ }^{4}$ Therefore, promoting habits of regular and adequate $\mathrm{F} \& \mathrm{~V}$ consumption is a priority public health goal.5,6

Despite these well-known benefits, consumption of $F \& V$, especially vegetables, remains low. Less than 1 in 10 adults meet dietary guidelines for $\mathrm{F} \& \mathrm{~V}$ consumption. ${ }^{7}$ Furthermore, the variety of F\&V consumed is very low. ${ }^{7}$ Orange juice comprises most of the overall fruit intake among adults and adolescents, and potatoes dominate vegetable consumption. ${ }^{8}$ Dark green and orange vegetables and legumes account for only a small portion of vegetable intake. ${ }^{9}$ Diets without a variety of whole fruits, dark greens and orange vegetables lack the full nutrient-rich and digestive benefits of F\&Vs. ${ }^{10}$

Low prevalence and diversity of vegetable consumption is similarly problematic among children. Although 24-hour dietary recall data from the NHANES surveys from 2003 to 2010 suggest that whole fruit intake increased over this period among 2-18 year olds, vegetable consumption remained constant. ${ }^{9}$ No socio-demographic group met the Healthy People 2020 target for vegetables [1.1 CEPC (cup-equivalents per 1,000 calories)], and only 2- to 5-year-old children met their target of 0.9 CEPC fruits. Furthermore, about a third of their vegetable intake was white potatoes, mostly eaten fried or as potato chips. ${ }^{9}$ These findings are concerning, given 
28 that preferences for foods and dietary habits in adulthood are established at an early age. ${ }^{11}$

29 Therefore, identifying factors and activities that are related to children's intake of vegetables is a 30 research and public health imperative.

31 Gardening is a promising strategy to improve children's dietary habits. The United States

32 (U.S.) has experienced a resurgence of home and community gardening activity similar to the

33 Victory Garden Movement; there has been a $17 \%$ increase in gardening over the past 5 years. ${ }^{12}$

34 The National Gardening Association (NGA) found that 42 million households in America are now

35 growing food at home or in a community garden, and 15 million of these households include

36 children as gardeners. ${ }^{12}$ However, home-based gardens require substantial time and resource

37 investment on the part of parents, and cannot be universally prescribed as a means of engaging

38 children in gardening. Similarly, although community gardens allow for the sharing of gardening

39 responsibilities, time commitment and resources in a way that facilitates participation by diverse

40 socio-demographic groups, ${ }^{13}$ community gardens require special coordination to host children.

41 School-based gardens are a solution tailored for children. Schools increasingly use gardens

42 as a popular teaching tool. ${ }^{14-17}$ According to the United States Department of Agriculture (USDA)'s

43 Farm-to-School Census, there are nearly 2400 documented school gardens across the U.S. ${ }^{18}$

44 School gardens range in their utility, combining classroom lessons across a diverse array of

45 subjects with experiential learning and hands-on outdoor activities. Research examining the

46 impact of school gardens on children's eating behavior shows positive trends in F\&V preference,

47 willingness to try vegetables, increased nutrition knowledge, and improved weight status. ${ }^{19-26}$

48 Given the interest in school garden programs as one increasingly popular strategy to improve

49 healthy eating among children, it is interesting to note that no studies specifically examining the 
50 association between gardening experience and healthy eating among groups of children have been

51 conducted. The main purpose of this paper is to fill this gap in the literature.

$52 \quad$ How much students enjoy their gardening experience may contribute to the potential

53 association between gardening experience and healthy eating. An evaluation of qualitative data

54 from 14 elementary schools participating in the Junior Master Gardener (JMG) program, a school-

55 based gardening program, showed that students enjoyed the program, shared what they learned

56 with others, and wanted to participate in more JMG and gardening-type activities. ${ }^{27}$ A 12 -week

57 pilot program at a YMCA summer camp found a very high level of child enjoyment in garden-

58 related activities (>95\%). ${ }^{23}$ Several studies have found enjoyment to be a positive predictor of

59 participation in other behaviors such as physical activity, but none have examined the relation

60 between levels of enjoyment of gardening and healthy eating. ${ }^{28-30}$ Thus, given the paucity of

61 research examining the relationships among gardening experience, level of enjoyment, and

62 healthy eating, the purpose of this paper is to examine these relationships among a group of

63 ethnically diverse elementary-school-age children.

64

65

66

67

68

69

70

71

72

73

74 activity) on the prevalence of healthy eating and physical activity behaviors and Body Mass Index

75 (BMI) among low-income 3rd grade students and parents. The present analyses examine the 
76 baseline student survey data prior to intervention. All recruitment and data collection procedures

77 and protocols were approved by each university's Institutional Review Board and by the

78 appropriate school districts' research authorities.

80 Participant Recruitment. Third grade students were recruited through elementary schools

81 which were located in five different counties in Texas during the months of September and

82 October in 2012 and 2013. All schools served a student population of which at least $40 \%$ were

83 living in low-income households, and $85 \%$ of children in the schools were eligible for Free and

84 Reduced Lunch. All third grade students received a TGEG study packet that they were asked to

85 take home and give to their parents. The TGEG study packet included a letter introducing the

86 Texas Grow! Eat! Go! study, parental consent forms for the child and parent to participate, a media

87 release form, and the TGEG Parent Survey. All documents were available in both English and

88 Spanish. Parents interested in having their child participate in the study were asked to complete

89 the parental consent form and return the packet to their child's teacher. Inclusion criteria for the

90 students were (1) enrollment in the $3^{\text {rd }}$ grade at a study school and (2) willingness to complete the

91 Student Survey four times during the study. Exclusion criteria includes (1) being on a special diet,

92 and (2) primary language not English or Spanish. Students received a small incentive worth

93 approximately $\$ 3.00$. Parents received no incentive.

94

95 Baseline Data Collection. At a time arranged with each school's administrative staff, the TGEG

96 research team collected both survey data (the TGEG Student Survey) and anthropometric data

97 (height and weight measurements) from all $3^{\text {rd }}$ grade students with signed parental consent.

98 Before any data collection occurred, each child was also asked to complete an assent form. Trained 
99 research staff proficient in both English and Spanish conducted all data collection and the TGEG

100 Student Survey was available in both English and Spanish languages.

102 Measures. For the present analysis, data related to child gardening experience, gardening 103 enjoyment, preference for vegetables, vegetable exposure, consumption of vegetables, and 104 demographic variables were obtained from the baseline TGEG Student Surveys. The TGEG 105 Student Survey is a self-administered survey (available in both English and Spanish) which 106 includes items and scales that have been previously validated. For the constructs for which no 107 previously validated measures were available, we developed them specifically for this study (i.e. 108 enjoyment of gardening). The Student Survey was pilot-tested with 59 students. ${ }^{31}$ Several changes 109 were made based on feedback from teachers and children, including the wording of a few 110 questions and the addition of a picture-guided facilitation for the scale measuring vegetable 111 preference.

113 Gardening Experience. The Gardening Experience scale included five items, developed 114 specifically for this study, asking the student if s/he participated in any of the following activities 115 with members of their family in the past year: planned a vegetable garden, planted seeds or plants, 116 picked vegetables from a garden, tasted vegetables from a garden, or pulled weeds or watered 117 plants in a garden. Response options for each of the questions included "Yes" or "No." A principal 118 components analysis indicated only one underlying factor (data not shown), hence all items were 119 combined into a single index. Binary responses to the five items were coded 0 or 1 , and summed 120 into an index score [range: 0 to 5, with a mean of 2.1 and a standard deviation (SD) of 1.9]. To 121 facilitate trend analysis, the responses for this scale were collapsed to three categories, indicating 
122 "No gardening experience" (scale score=0), "Medium gardening experience" (scale score 1-2), and

123 "High gardening experience" (scale score 3-5). Cut points for these categories were selected such

124 that each category comprised approximately a third of the sample.

126 Gardening Enjoyment. A single item specifically developed for this study examined students' 127 enjoyment for gardening by asking whether students enjoyed gardening with members of their 128 family. Response options included "Yes," "No," or "I have never gardened." The gardening 129 enjoyment measure was only computed for the 911 (69\%) children who reported any experience 130 with gardening. The range for this item was $0-1$ with a mean of 0.8 and a SD of 0.3 .

Vegetable Exposure. To measure Vegetable Exposure and Vegetable Preference (see below), we 133 used a validated scale developed by Baranowski et al. (2000), which we adapted for our study. ${ }^{32}$ 134 The adaptations involved inclusion of a different set of vegetables (ones that were specifically 135 featured in the TGEG school garden curriculum) and different response options. The scale 136 measured exposure for 19 vegetables commonly consumed by children and featured in the TGEG 137 intervention and included vegetables such as corn, lettuce, carrots, cabbage, broccoli, beets, 138 squash, and green beans. ${ }^{35}$ For each vegetable, the student indicated first whether they had ever 139 eaten the specific vegetable measured by a "Yes" or "No" response. To increase validity of the 140 students' responses we showed the children pictures of each vegetable in both raw and cooked 141 form. Responses were summed to calculate a Vegetable Exposure score. The mean score for this 142 variable in the TGEG sample was 12.2 ( $\mathrm{SD}=4.0$, range $0-19)$. The Cronbach Alpha for this scale was 1430.8. 
145 Preference for Vegetables. The Preference for Vegetables scale measured preference for the 146 same set of items as used for the Vegetable Exposure assessment. After the student indicated 147 whether they had ever eaten the given vegetable measured by a "Yes" or "No" response, they were 148 asked if they liked the given vegetable measured by "Yes," "No," or "I don't know" as indicated 149 with "smiley" faces. Responses were summed for a Vegetable Preference Scale Score. Mean score 150 for this variable in the TGEG sample was $8.9(\mathrm{SD}=4.1$, range $0-19)$. The Cronbach Alpha for this 151 scale was 0.8.

153 Vegetable Consumption. Three items in the TGEG Student Survey examined consumption of 154 vegetables. The items were based on a vegetable item originally developed for the School Based 155 Nutrition Monitoring Study (SBNM) survey, which has been previously validated with $4^{\text {th }}$ grade 156 students. ${ }^{33}$ The Vegetable Consumption items ask the student to indicate the frequency of 157 consumption of a given vegetable on the previous day in the following format: "Yesterday, did you 158 eat any [vegetable category]?" The categories included (1) "orange vegetables like carrots, squash, 159 or sweet potatoes?"; (2) "salad made with lettuce, or any green vegetables like spinach, collard 160 greens, Swiss chard, green beans, sugar snap peas, broccoli, or other greens?"; and (3) "any other 161 vegetables like tomatoes, asparagus, red cabbage, cauliflower, cucumbers, mushrooms, green or 162 bell peppers, eggplant, or celery?" For each item, a graded set of response options including, "no, I 163 did not eat any of [vegetable category] yesterday;" "yes, I ate [vegetable category] 1 time 164 yesterday;" "yes, I ate [vegetable category] 2 times yesterday;" and "yes, I ate [vegetable category] 1653 or more times yesterday" was available. Analyses were conducted with the vegetable 166 consumption items summed together as a scale and as 3 separate items. The mean score for 
167 previous day vegetable consumption scale was $2.6(\mathrm{SD}=2.5$, range $0-3)$. The Cronbach alpha was $168 \quad 0.7$.

170 Height and weight data. Trained research staff used standard equipment (digital Tanita scale

171 and stadiometer) and calibration procedures to measure body weight to the nearest $0.1 \mathrm{~kg}$ and 172 height to the nearest $1 \mathrm{~mm}$ as described in the National Center for Health Statistics. ${ }^{34}$ Age- and 173 sex-specific body mass index (BMI) percentiles were computed using the 2000 CDC reference 174 chart. 35

176 Demographic data. Students were asked to report their gender, ethnicity, and age on the 177 demographic section of the TGEG Student Survey.

179 Data Analysis. Random effects regressions adjusting for gender, ethnicity, age, and BMI 180 percentile of child, as well as for possible clustering of outcomes at the school level, were used to 181 evaluate associations of vegetable exposure, preference, and consumption with gardening 182 experience and gardening enjoyment. Models that examined gardening enjoyment were limited to 183911 children who stated that they had any gardening experience, while models examining 184 gardening experience included all 1326 children measured at baseline. Choice of regression 185 confounders was based on literature suggesting differences in outcome variables by these 186 confounders. Participants missing data on one or more covariates, or on the outcome variable, 187 were excluded from the regressions by automatic list-wise deletion. The outcome measures of 188 vegetable exposure and preference had no missing data. Fewer than $2 \%$ of the participants had 
189 missing data on consumption of each of the individual vegetable categories, and missing values

190 were set to zero in the summed vegetable consumption measure.

191

192

193

194 Description of participants. Third grade students $(n=1326)$ from 28 elementary schools

\section{RESULTS} participated in the baseline data collection. Our recruitment goal for the study was 50 students

per school. The actual recruitment per school ranged from 17 to 85 students per school, for an average of approximately 47 students per school.

Table 1 provides demographic characteristics of the student participants $(n=1326)$, according to child-reported gardening experience and enjoyment. The participants who provided complete data were evenly divided by gender ( $51 \%$ girls), and the majority were 8 years old (71\%). Forty percent of students identified themselves as ethnically Hispanic.

One third of the students $(n=414)$ had no prior garden experience, and a slightly smaller percentage $(27 \%, n=360)$ reported 1 to 2 types of gardening experience. The largest category was students reporting having 3 or more types of gardening experience $(42 \%, n=551)$. A greater proportion of girls (45\%) reported 3 or more experiences compared to boys. Of the 911 children who did respond having experience gardening, a large percentage of students (65\%) reported that they did enjoy gardening. This was nearly equal for boys and girls. A greater proportion of Hispanics enjoyed gardening compared to other ethnic/racial groups.

Table 2 presents estimated vegetable exposure, vegetable preference, and vegetable consumption according to different levels of gardening experience. Participants with higher levels of gardening experiences reported consuming vegetables an average of 3.5 times on the previous day compared to 1.7 times reported by children with no prior gardening experience $(P<0.001)$. 
213 The same pattern of higher vegetable consumption with higher gardening experience was seen

214 when examining consumption within individual categories of vegetables. Children who had a

215 score of 3 or more for gardening experience also reported greater exposure to and preference for

216 vegetables compared to children with no gardening experience $(P<0.001)$. The same patterns

217 were seen when comparing children with medium gardening exposure and the outcome variables 218 except for vegetable exposure.

219 Table 3 presents results among children who reported having some gardening experience.

220 Children who enjoyed gardening reported having greater exposure to vegetables $(P<.001)$ and

221 greater preference for vegetables $(P<.001)$ than children with gardening experience but who did

222 not enjoy it. In addition, children who reported having gardened and enjoyed gardening ate

223 significantly more vegetables on the previous day compared to children who did not enjoy

224 gardening $(P<.001)$. This pattern held true for individual categories of vegetables. Children who

225 had experienced, but did not enjoy gardening, still had slightly higher consumption of vegetables

226 and fruits, compared to children who had never had gardening experience (data not shown).

The purpose of this analysis was to explore the relationships between gardening experience and 232 enjoyment and vegetables exposure, preference, and consumption among children prior to their 233 participation in the TGEG study. The results show that in a large, diverse sample of 3rd grade 234 students in Texas, approximately $31 \%$ of children did not have any gardening experience. Of the 235 two thirds of the sample who did have gardening experience, $42 \%$ had multiple experiences with 236 gardening. 
Children who reported more gardening experiences consumed significantly more vegetables and reported a higher preference and exposure to vegetables compared to children who reported not having any experience. In a meta-analysis of garden-based nutrition interventions by Langellotto and Gupta (2012), the authors concluded that gardening increased

241 vegetable consumption in children. ${ }^{15}$ The authors provide two hypotheses that explain their 242 results: (1) gardening increases access to vegetables and (2) gardening decreases children's

243 reluctance to try new foods. Our results directly support their main result that gardening

244 experience is related to more vegetable consumption and indirectly supports their second

245 hypothesis. More recent garden-based intervention studies confirm the review's findings and

246 indicate an increase in vegetable consumption and preference upon completion of the

247 intervention. ${ }^{26,36,37}$ Although garden-based interventions normally include more components than 248 just gardening, it is likely that gardening experience has some influence on the observed increase 249 in vegetable consumption.

In addition to the high levels of gardening experience reported by the students, $65 \%$ of

251 participants also reported that they enjoyed gardening. This finding is consistent with results

252 from other studies, which indicate that children do enjoy gardening. ${ }^{21}$ Among the children in our

253 sample who reported enjoyment of gardening, their reported preferences for vegetables and

254 consumption of vegetables was greater compared to children who reported not enjoying

255 gardening. This finding implies that school-based garden interventions are potentially more

256 effective when the garden experience is enjoyable.

257 Given the tremendous increase of school gardens at schools in the U.S., this study provides 258 some insight on the mechanism explaining how school gardens may increase children's vegetable 259 consumption. Even though the gardening experience reported by the children was not necessarily 
260 gardening experienced at school, these findings potentially have implications for the importance

261 of school gardens as interventions to increase children's healthy eating. Given the associations

262 found in this study, one strategy for schools to promote healthier eating among their students

263 includes providing enjoyable opportunities for students to work in gardens. Strengths of the study

264 include the inclusion of low-income and ethnically diverse children.

265 This baseline analysis was conducted using data from the TGEG intervention study prior to

266 the implementation of the intervention. Associations found do not imply causality and need to be

267 interpreted with this limitation in mind. In this analysis, gardening experience and enjoyment

268 were measured using self-report scales developed for the TGEG study. Given that our study

269 participants were young (ages 8-10), the responses may have been subject to recall bias or social

270 desirability. As with any self-report instrument, students may have over or under reported their

271 responses. Although the tools were pilot-tested with $3^{\text {rd }}$ grade children in both English and

272 Spanish, they have not been formally validated. For future use, the scales/items should be

273 validated in order to rule out measurement and response bias. In addition, using only one item to

274 measure a specific construct (i.e. gardening enjoyment) is not ideal. However, in order to reduce

275 response burden, we needed to limit the number of items included on the survey. Lastly, there are

276 potential confounding factors (such as parent exposure to vegetable gardening, presence of

277 gardens at home, access to gardens at the time of the study) that may have confounded the results.

278 However, as mentioned above, given that we needed to limit the number of items on the survey

279 because of age of children, we needed to be selective with the number of items we included on the 280 survey and were not able to include all the items of interest. 
284 The results presented in this paper provide a unique snapshot of the level of gardening 285 experience and enjoyment of gardening among a diverse sample of children attending public 286 schools, as well as a deeper understanding of the mechanism of how garden-related activities may 287 be associated with precursors to vegetable consumption. These results suggest the importance of 288 making garden-based interventions engaging and dynamic in order to increase enjoyment of 289 gardening for children to participate and engage in learning that could lead to behavior change. 290 This study is the first of its kind to examine garden-related factors among an ethnically diverse, 291 low-income population of children, an understudied group and one for whom improving nutrition 292 could help narrow health disparities. 


\section{REFERENCES}

1. Willett WC. Fruits, vegetables, and cancer prevention: turmoil in the produce section. J Natl Cancer Inst. 2010;102(8):510-511.

2. Carter P, Gray LJ, Troughton J, Khunti K, Davies MJ. Fruit and vegetable intake and incidence of type 2 diabetes mellitus: systematic review and meta-analysis. $B M J$. 2010;341:c4229.

$3013 . \quad$ Wang X, Ouyang Y, Liu J, et al. Fruit and vegetable consumption and mortality from all causes, cardiovascular disease, and cancer: systematic review and dose-response meta-

4. Slavin JL, Lloyd B. Health benefits of fruits and vegetables. Advances in Nutrition: An International Review Journal. 2012;3(4):506-516.

5. Health.gov. Dietary Guidelines. 2010; http://health.gov/dietaryguidelines/2015/. Accessed December 14, 2015.

6. HealthyPeople.gov. Strategies to Prevent Obesity and Other Chronic Diseases: The CDC

7. Kimmons J, Gillespie C, Seymour J, Serdula M, Blanck HM. Fruit and vegetable intake among adolescents and adults in the United States: percentage meeting individualized recommendations. Medscape J Med. 2009;11(1):26.

8. Lee SG, Lloyd B, Wang Y, Yang M, Chung S-J, Chun OK. Orange juice consumption is associated with enhanced antioxidant intake status in the US population: a cross-sectional study. The FASEB Journal. 2012;26(1_MeetingAbstracts):1009.1003. 
318 9. Kim SA, Moore LV, Galuska D, et al. Vital signs: fruit and vegetable intake among children 319 United States, 2003-2010. MMWR Morb Mortal Wkly Rep. 2014;63(31):671-676.

320 10. Liu RH. Health-promoting components of fruits and vegetables in the diet. Adv Nutr. $321 \quad 2013 ; 4(3): 384 S-392 S$.

322 11. Northstone K, Emmett P. Multivariate analysis of diet in children at four and seven years of 323

12. National Gardening Association. Food Gardening in the U.S. at the Highest Levels in More Than a Decade According to New Report by the National Gardening Association. 2014; http://assoc.garden.org/press/press.php?q=show\&id=3819\&pr=pr nga. Accessed December 10, 2015.

13. Barnidge EK, Hipp PR, Estlund A, Duggan K, Barnhart KJ, Brownson RC. Association between community garden participation and fruit and vegetable consumption in rural Missouri. Int J Behav Nutr Phys Act. 2013;10:128.

14. Davis JN, Spaniol MR, Somerset S. Sustenance and sustainability: maximizing the impact of school gardens on health outcomes. Public Health Nutr. 2015;18(13):2358-2367.

336 16. Ozer EJ. The effects of school gardens on students and schools: conceptualization and considerations for maximizing healthy development. Health Educ Behav. 2007;34(6):846-

339 17. Robinson-O'Brien R, Story M, Heim S. Impact of garden-based youth nutrition intervention $340 \quad$ programs: a review. J Am Diet Assoc. 2009;109(2):273-280. 
341 18. United States Department of Agriculture. Bringing the farm to school. 2015;

342 http://www.fns.usda.gov/farmtoschool/census - /. Accessed 2015, December 14.

343 19. Davis JN, Ventura EE, Cook LT, Gyllenhammer LE, Gatto NM. LA Sprouts: a gardening, 344 nutrition, and cooking intervention for Latino youth improves diet and reduces obesity. $J$ $345 \quad$ Am Diet Assoc. 2011;111(8):1224-1230.

346 20. Beckman LL, Smith C. An Evaluation of Inner-City Youth Garden Program Participants' 347 Dietary Behavior and Garden and Nutrition Knowledge. Journal of Agricultural Education. $348 \quad 2008 ; 49(4): 11-24$.

349 21. Heim S, Stang J, Ireland M. A garden pilot project enhances fruit and vegetable consumption 350 among children. Journal of the American Dietetic Association. 2009;109(7):1220-1226.

351 22. Hermann JR, Parker SP, Brown BJ, Siewe YJ, Denney BA, Walker SJ. After-school gardening 352 improves children's reported vegetable intake and physical activity. J Nutr Educ Behav. $353 \quad 2006 ; 38(3): 201-202$.

354 23. Koch S, Waliczek TM, Zajicek JM. The effect of a summer garden program on the nutritional 355 knowledge, attitudes, and behaviors of children. HortTechnology. 2006;16(4):620-625.

356 24. McAleese JD, Rankin LL. Garden-based nutrition education affects fruit and vegetable 357 consumption in sixth-grade adolescents. J Am Diet Assoc. 2007;107(4):662-665.

358 25. Ratcliffe MM, Merrigan KA, Rogers BL, Goldberg JP. The effects of school garden 359 experiences on middle school-aged students' knowledge, attitudes, and behaviors 360 associated with vegetable consumption. Health Promot Pract. 2011;12(1):36-43. 361 26. Gatto NM, Martinez LC, Spruijt-Metz D, Davis JN. LA sprouts randomized controlled 362 nutrition and gardening program reduces obesity and metabolic risk in Latino youth. $363 \quad$ Obesity (Silver Spring). 2015;23(6):1244-1251. 
364 27. Dirks AE, Orvis K. An evaluation of the Junior Master Gardener program in third grade 365 classrooms. HortTechnology. 2005;15(3):443-447.

366 28. Craig S, Goldberg J, Dietz WH. Psychosocial correlates of physical activity among fifth and 367 eighth graders. Prev Med. 1996;25(5):506-513.

368 29. DiLorenzo TM, Stucky-Ropp RC, Vander Wal JS, Gotham HJ. Determinants of exercise 369 among children. II. A longitudinal analysis. Prev Med. 1998;27(3):470-477.

370 30. Dishman RK, Motl RW, Saunders R, et al. Enjoyment mediates effects of a school-based 371 physical-activity intervention. Med Sci Sports Exerc. 2005;37(3):478-487.

372 31. Spears-Lanoix EC, McKyer EL, Evans A, et al. Using Family-Focused Garden, Nutrition, and 373 Physical Activity Programs To Reduce Childhood Obesity: The Texas! Go! Eat! Grow! Pilot 374 375 376 Study. Child Obes. 2015;11(6):707-714.

32. Baranowski T, Davis M, Resnicow K, et al. Gimme 5 fruit, juice, and vegetables for fun and health: outcome evaluation. Health Educ Behav. 2000;27(1):96-111.

33. Penkilo M, George GC, Hoelscher DM. Reproducibility of the School-Based Nutrition Monitoring Questionnaire among fourth-grade students in Texas. J Nutr Educ Behav. 2008;40(1):20-27.

34. Center for Disease Control and Prevention. http://www.cdc.gov/healthyweight/assessing/bmi/childrens_bmi/measuring_children.ht ml/\#Height. Accessed June 17, 2016.

383 35. Kuczmarski RJ, Ogden CL, Grummer-Strawn LM. CDC Growth Charts: United States. 384 Advance data from vital and health statistics; no.314. 2000. 
387 36. Duncan MJ, Eyre E, Bryant E, et al. The impact of a school-based gardening intervention on 388 intentions and behaviour related to fruit and vegetable consumption in children. J Health 389 Psychol. 2015;20(6):765-773.

390 37. Hutchinson J, Christian MS, Evans CE, Nykjaer C, Hancock N, Cade JE. Evaluation of the 391 impact of school gardening interventions on children's knowledge of and attitudes towards 392 fruit and vegetables. A cluster randomised controlled trial. Appetite. 2015;91:405-414. 
Table 1: Gardening Experience and Enjoyment of Gardening by Demographic Characteristics of Children ( $n=1326)$

\begin{tabular}{|c|c|c|c|c|c|c|c|c|c|c|}
\hline & \multicolumn{5}{|c|}{ CHILD REPORTED GARDENING EXPERIENCE $(n=1326)$} & & \multicolumn{4}{|c|}{ CHILD REPORTED GARDENING ENJOYMENT $(n=911)$} \\
\hline & & $\begin{array}{c}\text { gardening } \\
\text { experience } \\
\text { Frequencies } \\
(\%) \\
\end{array}$ & $\begin{array}{c}1-2 \\
\text { experiences } \\
\text { Frequencies } \\
(\%) \\
\end{array}$ & $\begin{array}{c}3 \text { or more } \\
\text { experiences } \\
\text { Frequencies } \\
(\%) \\
\end{array}$ & & & & $\begin{array}{c}\text { Does not enjoy } \\
\text { gardening } \\
\text { Frequencies } \\
(\%)\end{array}$ & $\begin{array}{c}\text { Enjoys } \\
\text { gardening } \\
\text { Frequencies } \\
(\%)\end{array}$ & \\
\hline & $\begin{array}{c}\mathrm{N} \text { of } \\
\text { subsampl } \\
\mathrm{e} \\
\end{array}$ & & & & & & $\begin{array}{c}\mathrm{N} \text { of } \\
\text { subsample }\end{array}$ & & & \\
\hline Total & 1326 & $414(31)$ & $360(27)$ & $551(42)$ & & Total & 911 & 317 (35) & $594(65)$ & \\
\hline Boy & 652 & $223(34)$ & $183(28)$ & $246(38)$ & & Boy & 429 & $165(38)$ & $264(62)$ & \\
\hline Girl & 673 & $191(28)$ & $177(26)$ & 305 (45) & $P=0.01$ & Girl & 482 & $152(32)$ & $330(68)$ & $P=0.03$ \\
\hline Black & 226 & $69(30)$ & $60(27)$ & $97(43)$ & & Black & 157 & $68(43)$ & $89(57)$ & \\
\hline Hispanic & 534 & $162(30)$ & $159(30)$ & $213(40)$ & & Hispanic & 371 & $140(38)$ & $231(62)$ & \\
\hline White & 250 & $82(33)$ & $63(25)$ & $105(42)$ & & White & 168 & $44(26)$ & $124(74)$ & \\
\hline Other & 246 & $78(32)$ & $62(25)$ & $106(43)$ & $P=0.78$ & Other & 169 & $50(30)$ & $119(70)$ & $P<0.01$ \\
\hline $\begin{array}{l}\text { Normal } \\
\text { weight }\end{array}$ & 633 & $202(32)$ & $166(26)$ & $265(42)$ & & $\begin{array}{c}\text { Normal } \\
\text { weight }\end{array}$ & 431 & $151(35)$ & $280(65)$ & \\
\hline Overweight & 231 & $68(29)$ & $71(31)$ & $92(40)$ & & Overweight & 163 & $59(36)$ & $104(64)$ & \\
\hline Obese & 367 & $112(31)$ & $103(28)$ & $152(41)$ & $P=0.77$ & Obese & 255 & $82(32)$ & $173(68)$ & $P=0.66$ \\
\hline
\end{tabular}




\begin{tabular}{|c|c|c|c|c|c|}
\hline & $\mathrm{CHII}$ & REPORTED GA & DENING EXPERI & VCE & \multirow[b]{2}{*}{$\begin{array}{l}\text { p for contrast } \\
\text { with no } \\
\text { gardening } \\
\text { experience }\end{array}$} \\
\hline & $\begin{array}{c}\text { No gardening } \\
\text { experience } \\
\text { (estimated value } \\
\text { of outcomes, SE) } \\
\text { ( } n=415 ; 31 \%)\end{array}$ & $\begin{array}{c}\text { Medium } \\
\text { gardening } \\
\text { experience } \\
(n=360 ; 27 \%)\end{array}$ & $\begin{array}{l}\text { p for } \\
\text { contrast with } \\
\text { no gardening } \\
\text { experience }\end{array}$ & $\begin{array}{l}\text { High gardening } \\
\text { experience } \\
(n=551 ; 42 \%)\end{array}$ & \\
\hline Vegetables Exposure (Mean, SE) & $11.4(0.27)$ & $11.8(0.28)$ & $P=0.13$ & $13.0(0.26)$ & $P<0.001$ \\
\hline Vegetable Preference (Mean, SE) & $7.8(0.21)$ & $8.6(0.22)$ & $P<0.001$ & $9.8(0.18)$ & $P<0.001$ \\
\hline Times vegetables eaten on previous day (Mean, SE) & $1.7(0.13)$ & $2.3(0.14)$ & $P<0.001$ & $3.5(0.12)$ & $P<0.001$ \\
\hline $\begin{array}{l}\text { Times orange vegetables eaten on previous day } \\
\text { (Mean, SE) }\end{array}$ & $0.7(0.06)$ & $0.9(0.06)$ & $P<0.001$ & $1.3(0.05)$ & $P<0.001$ \\
\hline $\begin{array}{l}\text { Times green vegetables eaten on previous day } \\
\text { (Mean, SE) }\end{array}$ & $0.5(0.06)$ & $0.7(0.06)$ & $P=0.03$ & $1.1(0.05)$ & $P<0.001$ \\
\hline $\begin{array}{l}\text { Times other vegetables eaten on previous day } \\
\text { (Mean, SE) }\end{array}$ & $0.5(0.06)$ & $0.7(0.06)$ & $P=0.02$ & $1.1(0.05)$ & $P<0.001$ \\
\hline
\end{tabular}

All estimates are obtained from random effects regression models adjusting for age, sex, ethnicity, BMI percentile and random school level effect. A p-value of 0.05 was set at the threshold for significance. 
TABLE 3: Estimated Vegetable Exposure, Preference and Consumption, according to Gardening Enjoyment among Children Who Have any Gardening Experience $(n=911)$

\begin{tabular}{|l|c|c|c|}
\hline & \multicolumn{2}{|c|}{ CHILD REPORTED GARDENING ENJOYMENT (N=911) } \\
\hline & $\begin{array}{c}\text { Does not enjoy } \\
\text { gardening } \\
(\mathbf{n = 3 1 7 ;} \mathbf{3 5 \% )}\end{array}$ & $\begin{array}{c}\text { Enjoys gardening } \\
\text { (n=594; 65\%) }\end{array}$ & P value \\
\hline Vegetables Exposure (mean, SE) & $11.7(0.3)$ & $13.0(0.2)$ & $P<0.001$ \\
\hline Vegetable Preference (mean, SE) & $8.4(0.2)$ & $9.9(0.2)$ & $P<0.001$ \\
\hline $\begin{array}{l}\text { Times vegetables eaten on } \\
\text { previous day (mean, SE) }\end{array}$ & $2.3(0.2)$ & $3.4(0.1)$ & $P<0.001$ \\
\hline $\begin{array}{l}\text { Orange vegetables eaten on } \\
\text { previous day (mean, SE) }\end{array}$ & $0.9(0.1)$ & $1.2(0.1)$ & $P<0.001$ \\
\hline $\begin{array}{l}\text { Green vegetables eaten on } \\
\text { previous day (mean, SE) }\end{array}$ & $0.7(0.1)$ & $1.0(0.1)$ & $P<0.001$ \\
\hline $\begin{array}{l}\text { Other vegetables eaten on } \\
\text { previous day (mean, SE) }\end{array}$ & $0.7(0.1)$ & $1.1(0.1)$ & $P<0.001$ \\
\hline
\end{tabular}

All estimates are obtained from random effects regression models adjusting for age, sex, ethnicity, BMI percentile and random school level effect. A p-value of 0.05 was set at the threshold for significance. 